\title{
Erratum to: Bacillus bingmayongensis sp. nov., isolated from the pit soil of Emperor Qin's Terra-cotta warriors in China
}

\author{
Bo Liu • Guo-Hong Liu • Gui-Ping Hu • \\ Cetin Sengonca - Nai-Quan Lin • \\ Jian-Yang Tang $\cdot$ Wei-Qi Tang $\cdot$ Ying-Zhi Lin
}

Published online: 21 March 2014

(C) Springer International Publishing Switzerland 2014

\section{Erratum to: Antonie van Leeuwenhoek (2014) 105:501-510 \\ DOI 10.1007/s10482-013-0102-3}

article. The correct representation has been provided in this erratum.

The given name and family name of author "Cetin Sengonca" have been wrongly identified in the original

The online version of the original article can be found under doi:10.1007/s10482-013-0102-3.

B. Liu $(\bowtie) \cdot$ G.-H. Liu · G.-P. Hu · J.-Y. Tang ·

Y.-Z. Lin

Agricultural Bio-Resource Institute, Fujian Academy of

Agricultural Sciences, Fuzhou 350003, Fujian,

People's Republic of China

e-mail: fzliubo@163.com

G.-P. Hu · N.-Q. Lin · W.-Q. Tang

Fujian Agricultural and Forest University, Fuzhou

350002, Fujian, People's Republic of China

C. Sengonca

Institut fuer Nutzpflanzenwissenschaften und

Ressourcenschutz (INRES), Phytomedizin-Entomologie

und Pflanzenschutz, Universitaet Bonn, Nussallee 9,

53115 Bonn, Germany 